\title{
Nutrição mineral, crescimento e teor de óleo essencial da menta em solu- ção nutritiva sob diferentes concentrações de fósforo e épocas de coleta
}

\author{
Carlos R. Rodrigues; Valdemar Faquin; Daniel Trevisan; José Eduardo B.P. Pinto; Suzan Kelly V. \\ Bertolucci; Tatiana Michlovská Rodrigues \\ UFLA, C. Postal 37, 37200-000 Lavras-MG; E-mail: carlos_rrodrigues@yahoo.com.br; vafaquin@ufla.br
}

\section{RESUMO}

Avaliou-se o efeito de concentrações de $\mathrm{P}$ e épocas de coleta sobre o crescimento, nutrição mineral e teor de óleo essencial da menta (Mentha piperita L.). O delineamento experimental foi em blocos casualizados com parcelas subdivididas, em esquema fatorial $2 \times 5$, sendo 2 épocas de coleta ( 65 e 95 dias de cultivo (DC)) e 5 concentrações de $\mathrm{P}$ na solução nutritiva $\left(6 ; 12 ; 18 ; 24\right.$ e $\left.30 \mathrm{mg} \mathrm{L}^{-1}\right)$, com 4 repetições. Foi determinada a massa seca de folhas (MSF), caules (MSC), raízes (MSR) e total (MST) e as relações folha:caule (F:C) e parte aérea:raiz (PA:R). Também, foi determinado o teor de óleo essencial em folhas frescas. Os níveis críticos foliares e acúmulo de nutrientes na parte aérea da menta foram estimados por meio da análise química das folhas e caules. As concentrações de P na solução influenciaram o crescimento e a produção de óleo essencial pela menta. Na coleta realizada aos 65 DC, apenas a MSF foi influenciada pelo $\mathrm{P}$, não se observando efeito sobre os teores de óleo essencial. Aos 95 DC, o aumento da concentração de $\mathrm{P}$ promoveu aumentos significativos na massa seca das partes e do total da menta e, também, nos teores de óleo essencial, sendo o teor máximo (2,192 dag $\mathrm{kg}^{-1}$ ) obtido com 19,50 mg L-1 de P. As maiores concentrações de P avaliadas ( 24 e $30 \mathrm{mg} \mathrm{L}^{-1}$ ), promoveram aumentos na produção de matéria fresca e seca da parte aérea da menta, mas, reduziram os teores de óleo essencial, devido ao efeito de diluição, não significando, portanto, ganhos de produção de óleo por planta. Os teores foliares dos nutrientes associados ao teor máximo de óleo aos 95 DC foram em g kg${ }^{-1}: \mathrm{N}=37,2 ;=3,9 ; \mathrm{K}=21,2 ; \mathrm{Ca}=9,3 ; \mathrm{Mg}=3,8 ; \mathrm{S}=3,0$; e, em mg kg-1 $: \mathrm{B}=35 ; \mathrm{Cu}=8 ; \mathrm{Fe}=323 ; \mathrm{Mn}=145 \mathrm{e} \mathrm{Zn}=22$. A exigência nutricional aos $95 \mathrm{DC}$ relacionada ao teor máximo de óleo essencial seguiu a sequiência: $\mathrm{N}>\mathrm{K}>\mathrm{Ca}>\mathrm{P}>\mathrm{Mg}>\mathrm{S}>\mathrm{Fe}>\mathrm{Mn}>\mathrm{B}>\mathrm{Zn}>\mathrm{Cu}$.

Palavras-chave: Mentha piperita L., nível crítico, exigência nutricional, óleo essencial.

\begin{abstract}
Mineral nutrition, growth and essential oil content of mint in nutrient solution under different phosphorus concentrations

The effect of $\mathrm{P}$ concentrations and harvest period upon the growth, mineral nutrition and essential oil content of mint (Mentha piperita L.) was evaluated. The experimental design was of randomized blocks in a split-plot scheme, in a $2 \times 5$ factorial with four replications, being two harvest periods (65 and 95 days of cultivation (DC)) and five concentrations of $\mathrm{P}$ in the nutrient solution (6; 12; 18; 24 and $30 \mathrm{mg} \mathrm{L}^{-1}$ ) evaluated. The leaves dry weight (MSF), stems dry weight (MRS), roots dry weight (MSR), total dry weight (MST), leaf:stem ratio (F:C) and aerial part:root ratio (PA:R) were evaluated. The essential oil content in fresh leaves was determined. The critical levels and nutrient accumulation in leaves and stems were estimated through leaves and stems chemical analysis. The level of P increased the leaf dry matter production 65 DC. At 95 DC, the $\mathrm{P}$ concentration in the nutrient solution, did significantly increase plant growth and essential oil content, the maximum essential oil content being (2.192 dag $\mathrm{kg}^{-1}$ ) obtained with $19.48 \mathrm{mg} \mathrm{L}^{-1}$ of P. The higher $\mathrm{P}$ concentration in nutrient solution $\left(24\right.$ and $\left.30 \mathrm{mg} \mathrm{L}^{-1}\right)$, increased the fresh and dry matter of the aerial portion of the plants, but, decreased the essential oil content. Due to the dilution effect, the increase of fresh and dry matter production did not result in an increase in the oil yield per plant. The critical levels of nutrients in the leaves corresponding to the maximum essential oil content at 95 DC in kg $^{-1}$ were: $\mathrm{N}=37,2 ; \mathrm{P}=3,9 ; \mathrm{K}=21,2 ; \mathrm{Ca}=9,3 ; \mathrm{Mg}=3,8 ; \mathrm{S}=3,0$ and, in $\mathrm{mg} \mathrm{kg}^{-1}: \mathrm{B}=35 ; \mathrm{Cu}=8 ; \mathrm{Fe}=323 ; \mathrm{Mn}=145$ and $\mathrm{Zn}=22$. The nutrients requested at $95 \mathrm{DC}$ related to the maximum essential oil content was: $\mathrm{N}>\mathrm{K}>\mathrm{Ca}>\mathrm{P}>\mathrm{Mg}>\mathrm{S}>\mathrm{Fe}>\mathrm{Mn}>\mathrm{B}>\mathrm{Zn}>\mathrm{Cu}$.
\end{abstract}

Keywords: Mentha piperita L., critical level, nutritional request, essential oil.

(Recebido para publicação em 26 de abril de 2003 e aceito em 30 de março de 2004)

$\mathrm{O}$ uso da fitoterapia vem crescendo no Brasil na ordem de 10 a $15 \%$ ao ano. Amentha (Mentha piperita L.), planta aromática da família Labiatae, produz óleo essencial rico em mentona (14-32\%) e mentol (30-50\%) (Cardoso et al., 2001). O mentol possui larga aplicação nas indústrias de alimentos, farmacêutica, de higiene e do tabaco. Comercializa-se por ano mais de 5.000 toneladas de óleo essencial de menta, perfazendo o total de US\$ 50 milhões ano-1 (Maia, 1998).

O fósforo é um elemento de dinâmica complexa em solos tropicais, sen- do o nutriente que mais limita a produção nessas regiões (Raij, 1991). No Brasil existem poucos estudos do efeito de doses de $\mathrm{P}$ e suas relações com outros nutrientes e do crescimento e teor de óleo essencial da menta. $\mathrm{O}$ fósforo tem função importante na composição do ATP, responsável pelo armazenamento e transporte de energia para processos endergônicos, como a síntese de compostos orgânicos e absorção ativa de nutrientes (Marschner, 1995). Para a síntese dos monoterpenos, principal constituinte do óleo essencial da menta, são necessárias várias reações de fosforilação, sendo que o principal doador de energia e íon fosfato para a reação é o ATP (Dragar e Menary, 1995). Conseqüentemente, em plantas deficientes em $\mathrm{P}$ haveria menor taxa de fosforilação, diminuindo assim a produção de monoterpenos que, segundo Cardoso et al. (2001), representa 90\% da constituição dos óleos essenciais. De maneira geral, o maior suprimento de $\mathrm{P}$ em plantas do gênero Mentha, não altera o teor de óleo essencial, onde o incremento na sua produção é conse- 
qüência do aumento da produção da parte aérea das plantas (Singh e Singh, 1968, Kothari et al., 1987, Subrahmanyam et al., 1992, Piccaglia et al., 1993). Singh e Singh (1968) demonstraram a importância do P no metabolismo dos carboidratos, tais como frutose, glucose, sacarose, açúcares redutores, aminoácidos e proteínas. Os autores relatam que a deficiência do $\mathrm{P}$ causa acúmulo de açúcares em todos os órgãos da planta de menta (Mentha arvensis L.), principalmente nas hastes. Os autores afirmam, também, que estas plantas quando cultivadas em condições de deficiência de fósforo apresentam menor número de folhas, de área foliar e de quantidade de material verde e seco.

$\mathrm{Na}$ maior parte das vezes a aplicação do P é realizada totalmente no plantio, devido à sua baixa mobilidade no solo. Para plantas de crescimento determinado, que absorvem quase todo o $\mathrm{P}$ no início do ciclo e depois o redistribuem, isto é de grande interesse. Porém, as plantas do gênero Mentha possuem crescimento indeterminado, apresentando portanto, comportamento diferenciado da marcha de absorção de P (Singh e Singh, 1971). Os autores também relatam que a Mentha arvensis L. var. piperascens Holms absorveu 77\% do P após 77 dias de crescimento. Segundo Singh e Singh (1989), após 77 dias do cultivo foi observado o maior teor de óleo essencial nas folhas, ou seja, próximo ao período de florescimento. Então, o período de maior absorção de $\mathrm{P}$ coincide com o período de maior síntese de óleo essencial.

O presente trabalho teve por objetivo verificar o efeito das concentrações de $\mathrm{P}$ na solução nutritiva e épocas de coleta sobre o crescimento, teor de óleo essencial e estado nutricional das plantas de menta.

\section{MATERIAL E MÉTODOS}

O experimento foi conduzido em casa de vegetação da Universidade Federal de Lavras. Cultivou-se a menta (Mentha piperita L.) em solução nutritiva, de 18/05 a 21/08/2002. As mudas foram obtidas no Horto de Plantas Medicinais da UFLA. Após a formação de raízes, as mudas com aproximadamen- te $7 \mathrm{~cm}$ de altura, foram transferidas para bandejas de $40 \mathrm{~L}$ contendo solução de Hoagland (Hoagland e Arnon, 1950) a $50 \%$ durante 20 dias, para adaptação, sem aplicação dos tratamentos. Posteriormente, as mudas foram selecionadas pela uniformidade, sendo cada conjunto de seis delas transplantadas, em espaçamento $10 \times 10 \mathrm{~cm}$, para cada bandeja plástica com capacidade de $15 \mathrm{~L}$ contendo solução básica de Hoagland a $75 \%$ com os respectivos tratamentos, recebendo arejamento constante. As plantas foram mantidas nos tratamentos durante 45 e 75 dias, totalizando 65 e 95 dias de cultivo (DC) para a primeira e segunda coletas, respectivamente. $\mathrm{O}$ volume das bandejas foi completado diariamente com água deionizada. A troca da solução foi realizada quando sua condutividade elétrica era reduzida para $30 \%$ da inicial. A condutividade elétrica no início do cultivo foi 1,$81 ; 1,72$; 1,$67 ; 1,65$ e $1,61 \mathrm{mS} \mathrm{cm}^{-1}$ para as soluções nutritivas com $30 ; 24 ; 18 ; 12$ e 6 $\mathrm{mg} \mathrm{L}^{-1}$ de $\mathrm{P}$, respectivamente, e as mesmas foram trocadas quando atingiam valores de 0,$55 ; 0,52 ; 0,51 ; 0,50$ e 0,49 $\mathrm{mS} \mathrm{cm}^{-1}$, respectivamente. $\mathrm{O} \mathrm{pH}$ foi ajustado diariamente para valores entre 5,5 e 6,0, pela adição de $\mathrm{HCl}$ ou $\mathrm{NaOH}$ $0,1 \mathrm{~N}$, quando necessário.

O delineamento experimental foi em blocos casualizados com parcela subdividida, em esquema fatorial $5 \times 2$, com quatro repetições, sendo cinco concentrações de P na solução nutritiva $(6 ; 12$; 18; 24 e $\left.30 \mathrm{mg} \mathrm{L}^{-1}\right)$, na parcela e duas épocas de coleta (65 e 95 DC), na subparcela.

Durante o período experimental foram feitas observações sobre o crescimento e o aparecimento de sintomas visuais. Em cada época de coleta (65 e 95 DC), uma das três plantas da subparcela foi separada em folhas, caules e raízes, secas em estufa de circulação forçada de ar a $65-70^{\circ} \mathrm{C}$ até peso constante, pesadas, obtendo-se a produção de massa seca de folhas (MSF), caules (MSC) e raízes (MSR). Foram determinadas, também, a massa seca total (MST) e as relações caule:folha (C:F) e parte aérea:raiz (PA:R). As análises químicas dos nutrientes nas folhas e caules foram realizadas segundo Malavolta $e t$ al. (1997). Nas outras duas plantas de cada subparcela foram destacadas as fo- lhas, as quais foram acondicionadas em sacos plásticos identificados e armazenadas em congelador a $-15^{\circ} \mathrm{C}$, até o momento da extração do óleo essencial.

Amostras de $50 \mathrm{~g}$ de folhas frescas foram utilizadas para a extração dos compostos voláteis. A técnica utilizada foi a hidrodestilação por uma hora, em aparelho de Clevenger modificado. Cerca de $16 \mathrm{ml}$ de hidrolato, recolhidos de cada hidrodestilação, foram submetidos à extração do óleo com três porções de $30 \mathrm{ml}$ de diclorometano em funil de separação. Os extratos orgânicos provenientes de cada fracionamento foram reunidos e secos com sulfato de magnésio anidro. O sal foi removido por filtração simples e o solvente evaporado em rotavapor. Os produtos obtidos da rotaevaporação foram transferidos para frascos de vidro de $5 \mathrm{ml}$ e levados à estufa a $30^{\circ} \mathrm{C}$ até a completa evaporação do solvente, sendo então, determinado, através de pesagem, o teor de óleo essencial (Cardoso et al., 2000).

Foi determinada a relação entre matéria fresca de folhas (MFF) e massa seca de folhas (MSF) através de secagem de 10 amostras, obtendo uma média de $22 \%$ de massa seca. Através desta, foi estimada a produção de óleo essencial por planta.

As variáveis analisadas foram submetidas à análise de variância e regressão com auxílio do programa SISVAR ${ }^{\circledR}$.

Para obter o efeito das concentrações de P na solução nutritiva, sobre as variáveis avaliadas aos 65 e 95 DC, modelos de regressão foram ajustados para os dados de produção de massa seca de folhas, caules, raízes e total, relações F:C e PA:R, teores de óleo essencial nas folhas e de nutrientes nas folhas e caules, como variáveis dependentes das concentrações de fósforo na solução. Como o teor foliar de óleo essencial é a variável de maior interesse industrial, estimou-se a concentração de P na solução correspondente ao máximo teor de óleo aos 95 DC. Substituindo-se essa concentração de P na solução, nas equações de regressão que relacionam os teores dos nutrientes na folhas e caules em função das concentrações de P, estimaram-se os teores nas folhas (níveis críticos) e nos caules dos macro e micronutrientes, correspondentes ao máximo 
teor de óleo aos 95 DC. O acúmulo de cada nutriente na parte aérea da menta foi calculado pela soma das quantidades acumuladas nos caules e nas folhas.

\section{RESULTADOS E DISCUSSÃO}

\section{Produção de Biomassa}

Para a primeira época de coleta (65 DC), a massa seca de folha (Figura 1a) apresentou uma resposta quadrática às concentrações de P na solução nutritiva, com a produção máxima estimada (8,36 g planta $\left.^{-1}\right)$ obtida com 18,68 mg $\mathrm{L}^{-1}$ de $\mathrm{P}$, e $90 \%$ da produção máxima (7,52 g planta $\left.^{-1}\right)$ obtida com $14,17 \mathrm{mg}$ $\mathrm{L}^{-1}$ de $\mathrm{P}$. Quanto à massa seca de caule, de raiz e total e à relação parte aérea:raiz, nessa época (65 DC), não foram influenciadas pelas concentrações de $\mathrm{P}$ (Figura 1b, c, d, f). A relação folha:caule, aos 65 DC, mostrou ajuste quadrático para as concentrações de $\mathrm{P}$ no meio (Figura 1e), sendo esse efeito um reflexo do comportamento da massa seca de folha às concentrações de $\mathrm{P}$ (Figura 1a) e à ausência de resposta da massa seca de caule (Figura 1b). As plantas que foram mantidas nos tratamentos com $6 \mathrm{e}$ $12 \mathrm{mg} \mathrm{L}^{-1}$ de $\mathrm{P}$ apresentaram, já aos 65 DC, redução de crescimento e início de sintomas visuais de deficiência de $\mathrm{P}$, tal como folhas mais ásperas e acentuação da cor roxa e hastes mais lenhosas. Esses sintomas são concordantes com os descritos por Singh e Singh (1968) e Maia (1994) para o gênero Mentha. Singh e Singh (1968) relatam que o baixo crescimento das plantas deficientes em P, está relacionado com o comprometimento na síntese de proteínas.

Na segunda época de coleta (95 DC), as concentrações de $\mathrm{P}$ na solução nutritiva influenciaram significativamente as variáveis avaliadas, com exceção das relações folha:caule e parte aérea:raiz (Figura 1e, f). As massas secas de folha, caule e total apresentaram ajuste linear positivo, enquanto para a massa seca de raiz o ajuste foi quadrático com a produção máxima estimada $(3,45 \mathrm{~g}$ planta $^{-1}$ ) obtida com $20 \mathrm{mg} \mathrm{L}^{-1}$ de $\mathrm{P}$, e $90 \%$ da produção máxima $(3,11 \mathrm{~g}$ plan$\left.\mathrm{ta}^{-1}\right)$ obtida com $15,45 \mathrm{mg} \mathrm{L}^{-1}$ de $\mathrm{P}\left(\mathrm{Fi}^{-}\right.$ gura 1a, b, c, d). Nessa época, os sintomas de deficiência de $\mathrm{P}$ das plantas dos tratamentos 6 e $12 \mathrm{mg} \mathrm{L}^{-1}$ de $\mathrm{P}$ foram

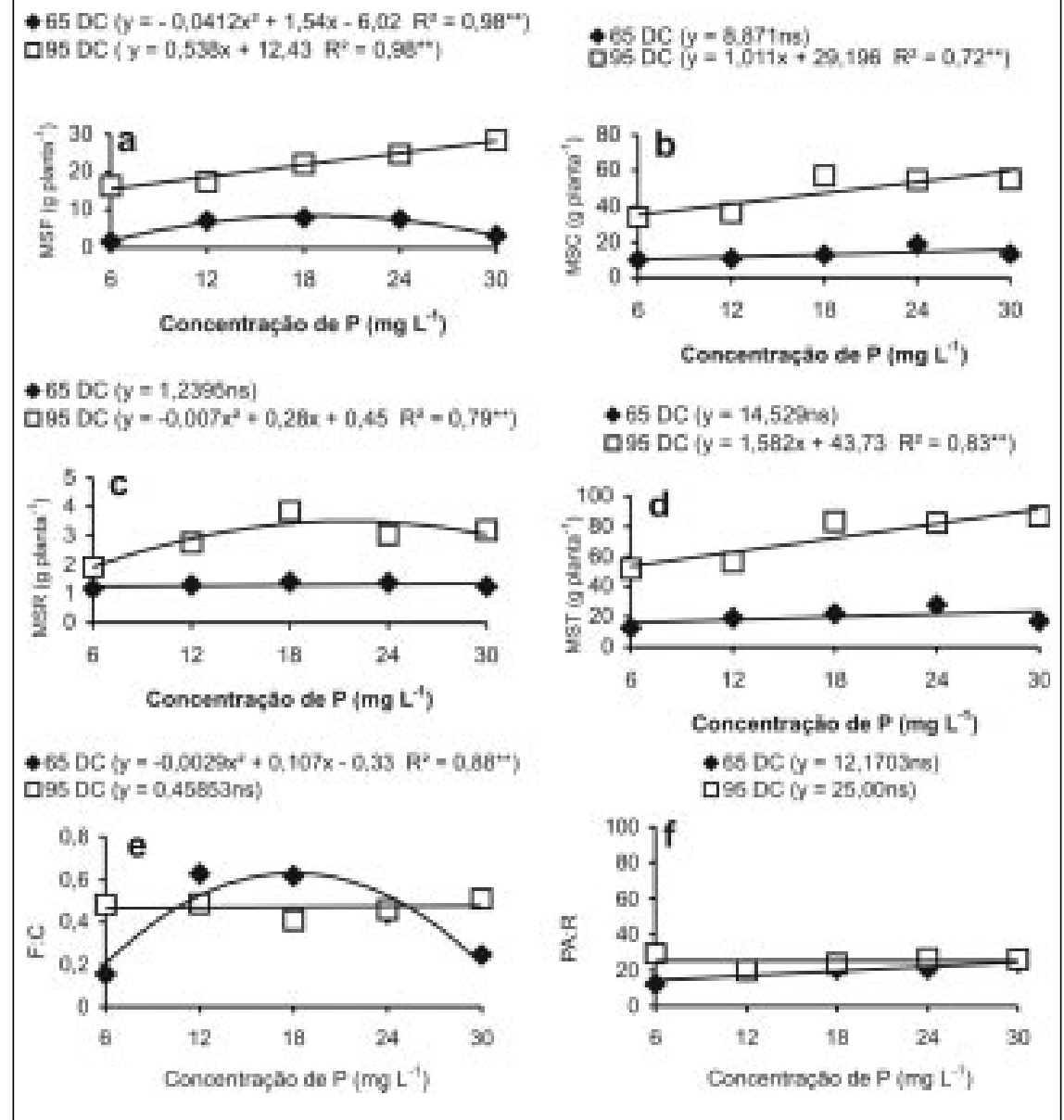

Figura 1. Produção de massa seca de folhas (a), caules (b), raízes (c) e total (d) e as relações folha:caule (e) e parte aérea:raiz (f), das plantas de menta coletadas aos 65 e 95 DC, em função da concentração de P na solução nutritiva. Lavras, UFLA, 2002.

acentuados, com coloração arroxeada em ambas as faces das folhas. As plantas mantidas na concentração de $18 \mathrm{mg}$ $\mathrm{L}^{-1}$ de $\mathrm{P}$ não mostraram sintomas característicos de deficiência.

Na Figura 1a observa-se diferença no comportamento da produção de massa seca de folha nas duas épocas avaliadas. Na segunda época de coleta, a maior concentração utilizada ( $30 \mathrm{mg} \mathrm{L}^{-1}$ de P) não foi suficiente para as plantas atingirem a máxima produção de massa seca foliar. Esse resultado é devido ao maior crescimento das plantas após os 65 dias de cultivo que, provavelmente, aumentou a exigência nutricional, não proporcionando o desequilíbrio nutricional para as plantas nas maiores concentrações de P no meio. Singh e Singh (1971) relatam que plantas do gênero Mentha são de crescimento indeterminado e que, de maneira geral, absorvem maior parte do $\mathrm{P}$ durante o período de pré-floração e floração. Com isso, durante a fase de desenvolvimento vegetativo não há necessidade de altas concentrações de $\mathrm{P}$ para as plantas atingirem a máxima produção, como observado para a produção de massa seca de folha aos 65 DC (Figura 1a). Em fases mais avançadas de desenvolvimento, as plantas necessitam de maiores quantidades de $\mathrm{P}$, o que é confirmado pelo efeito linear às concentrações de $\mathrm{P}$ no meio para a produção de massa seca de folha, aos 95 DC.

Embora as concentrações de $\mathrm{P}$ na solução nutritiva tenham aumentado a produção de massa seca de folha e caule, esse aumento foi proporcional entre as partes, pois a relação folha:caule não foi influenciada pela concentração do nutriente no meio aos 95 DC (Figura 1e). A relação parte aérea:raiz também não foi influenciada pelas concentrações de $\mathrm{P}$ da solução nutritiva (Figura 1f). Mesmo assim, observa-se aos 95 DC, que a 


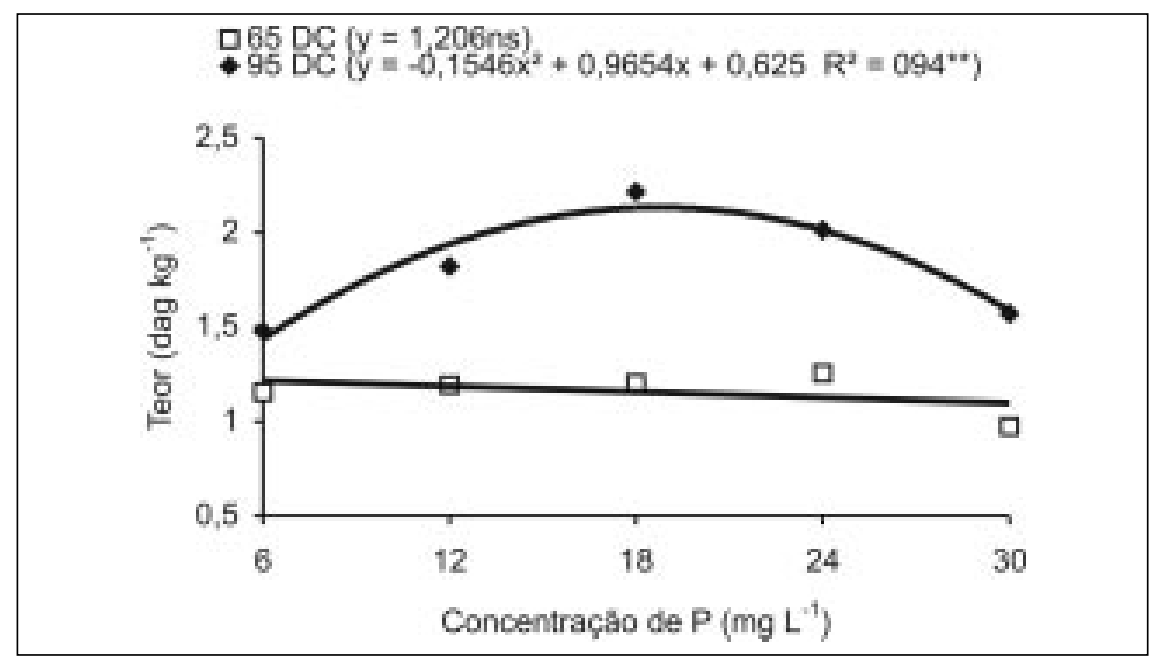

Figura 2. Teor $\left(\mathrm{dag} \mathrm{kg}^{-1}\right)$ de óleo essencial nas folhas frescas da menta, aos 65 e 95 DC, em função da concentração de P na solução nutritiva. Lavras, UFLA, 2002.

Tabela 1. Produção estimada de massa seca (MSF) e fresca de folhas (MFF), teor foliar e quantidade de óleo essencial por planta, nas concentrações de P na solução correspondentes à maior produção de $\mathrm{MSF}\left(30 \mathrm{mg} \mathrm{L}^{-1}\right)$ e ao máximo teor foliar de óleo essencial $(19,48 \mathrm{mg}$ $\left.\mathrm{L}^{-1}\right)$, aos 95 DC. Lavras, UFLA, 2002.

\begin{tabular}{|c|c|c|c|c|}
\hline \multirow{2}{*}{$P\left(\mathrm{mg} \mathrm{L}^{-1}\right)$} & MSF & MFF & \multirow{2}{*}{$\begin{array}{r}\text { Teor óleo } \\
\text { dag kg }^{-1}\end{array}$} & \multirow{2}{*}{$\begin{array}{c}\text { Óleo planta-1 }^{-1} \\
\text { mg planta- }^{-1}\end{array}$} \\
\hline & \multicolumn{2}{|c|}{ g planta $^{-1}$} & & \\
\hline 19,48 & 22,91 & 103,24 & 2,192 & 2263,02 \\
\hline 30,00 & 28,57 & 128,75 & 1,735 & 2234,00 \\
\hline Diferença (\%)* & $+24,70$ & $+24,70$ & $-26,33$ & $-1,30$ \\
\hline
\end{tabular}

*Diferença percentual das variáveis avaliadas entre as concentrações de $\mathrm{P}$. ,+ - aumento e redução, respectivamente.

maior concentração de $\mathrm{P}$ utilizada, 30 $\mathrm{mg} \mathrm{L}^{-1}$, não foi suficiente para atingir a máxima produção de massa seca de folha (Figura 1a), e a máxima produção de massa seca de raiz foi obtida com 21,46 $\mathrm{mg} \mathrm{L}^{-1}$ de $\mathrm{P}$ (Figura 1c). Esse resultado é de interesse dos produtores e das industrias, pois a menta, quando bem nutrida em $\mathrm{P}$, responde em maior produção de folha e de caule, que de raiz.

\section{Óleo Essencial}

As concentrações de P não influenciaram os teores de óleo essencial nas plantas da primeira época de coleta, enquanto que na segunda época, a resposta foi quadrática (Figura 2).

Os maiores teores de óleo essencial aos 95 DC são concordantes com alguns autores que relatam maiores teores de óleo essencial a partir de 75 dias de crescimento (Singh e Singh, 1968) e que o $\mathrm{P}$ influencia diretamente a síntese de óleo essencial (Dragar e Menary, 1995). Esses autores, trabalhando com Olearia phlogopappa observaram que em bai- xos níveis de $\mathrm{P}$, houve redução no teor de monoterpenos, principal constituinte do óleo essencial. A deficiência de $\mathrm{P}$ na planta, reduziria a fosforilação requerida para a produção de geranilpirofosfato, que é o precursor dos monoterpenos.

Pela equação de regressão da Figura 2, estimou-se a concentração de $\mathrm{P}$ na solução nutritiva e o teor de óleo essencial correspondente ao ponto de máxima para as plantas da segunda época de coleta (95 DC), que foram, respectivamente, de 19,48 $\mathrm{mg} \mathrm{L}^{-1}$ e 2,192 dag kg-1 de massa fresca de folha (MFF). A redução do teor de óleo essencial das plantas mantidas nas maiores concentrações de $\mathrm{P}$, pode estar relacionado ao efeito de diluição, devido à maior produção de folhas nessas concentrações (Figura 1a). Alguns autores relatam que o cultivo de plantas do gênero Mentha com altas doses de $\mathrm{P}$ apresentam menores concentrações de óleo essencial (Kothari et al., 1987; Subrahmanyam et al., 1992 e
Praszna e Bernáth, 1993). Esses autores relatam, ainda, que o aumento na produção de óleo essencial pela Mentha sp. nas altas doses de P está relacionado ao incremento da produção de folhas.

Ressalta-se que a concentração de $\mathrm{P}$ no meio que proporcionou o máximo teor de óleo essencial também produziu plantas sem sintomas visuais de deficiência de P. Esse resultado é de grande interesse para a indústria, que comprará matéria-prima com bom aspecto visual, e também para o produtor, que além disso, vai ganhar em qualidade da planta, isto é, alta concentração de princípio ativo.

Como já discutido, a massa seca de folhas, órgãos dos quais se extraem o óleo essencial, apresentou uma resposta linear às concentrações de $\mathrm{P}$ na solução aos 95 DC (Figura 1a), ou seja, não atingiu a produção máxima, no intervalo de concentrações de $\mathrm{P}$ testadas no experimento. Apenas para discussão da relação custo/benefício e destacar o efeito de diluição do óleo essencial nas folhas da menta na maior concentração de $\mathrm{P}$ usada na solução, através das equações de regressão da Figura 1a para MSF e Figura 2, para óleo essencial, ambas aos 95 DC, estimaram-se a massa seca de folhas e o teor foliar de óleo correspondentes a 19,48 e $30 \mathrm{mg} \mathrm{L}^{-1}$ de P (Tabela 1).

Observa-se que a concentração de $\mathrm{P}$ de $30 \mathrm{mg} \mathrm{L}^{-1}$, em relação à de $19,48 \mathrm{mg}$ $\mathrm{L}^{-1}$, promoveu um aumento da MSF $(24,70 \%)$, mas reduziu o teor foliar de óleo $(26,33 \%)$, ou seja, houve diluição do óleo pelo maior crescimento das folhas.

A estimativa da quantidade de óleo produzido por planta nos dois níveis de $P$ na solução $\left(19,48\right.$ e $\left.30 \mathrm{mg} \mathrm{L}^{-1}\right)$, foi determinada através da relação entre massa fresca de folhas (MFF) e massa seca de folhas (MSF).

Observa-se pelos valores estimados (Tabela 1), que a diluição do teor foliar de óleo foi proporcional ao crescimento das folhas, obtendo-se praticamente a mesma quantidade de óleo por planta, nos dois níveis de fósforo na solução.

Pelos valores obtidos, pode-se inferir que a concentração de $\mathrm{P}$ no meio que proporcionou o teor máximo de óleo nas folhas $\left(19,48 \mathrm{mg} \mathrm{L}^{-1}\right)$, embora insuficiente para o adequado crescimento 
Tabela 2. Equações de regressão para os teores nas folhas e caules (Y) dos macro $\left(\mathrm{g} \mathrm{kg}^{-1}\right)$ e micronutrientes $\left(\mathrm{mg} \mathrm{kg}^{-1}\right)$, como variáveis dependentes das concentrações de $\mathrm{P}$ na solução nutritiva $\left(\mathrm{mg} \mathrm{L}^{-1}\right)$, teores foliares (níveis críticos) e acúmulo dos nutrientes na parte aérea (folha + caule) da menta, correspondentes ao máximo teor foliar de óleo essencial, aos 95 DC. Lavras, UFLA, 2002.

\begin{tabular}{|c|c|c|c|c|c|}
\hline Nutriente & Órgão & Equações & R2 & Nível Crítico & Acúmulo \\
\hline \multirow[t]{3}{*}{$\mathrm{N}$} & Folha & $N=-0,017 P 2+0,94 P+25,28$ & $0,72^{* *}$ & 37,2 & 0,84 \\
\hline & Caule & $N=0,1494 P+13,199$ & $0,72^{* *}$ & - & 0,76 \\
\hline & & & & & 1,501 \\
\hline \multirow[t]{3}{*}{$\mathrm{P}$} & Folha & $P=0,0914 P+2,143$ & $0,96^{* *}$ & 3,9 & 0,09 \\
\hline & Caule & $P=0,0729 P+0,938$ & $0,98^{* *}$ & - & 0,11 \\
\hline & & & & & 0,20 \\
\hline \multirow[t]{3}{*}{$\mathrm{K}$} & Folha & $K=-0,08038 P+23,24$ & $0,77^{*}$ & 21,2 & 0,48 \\
\hline & Caule & $\mathrm{K}=17,404 \mathrm{~ns}$ & - & - & 0,82 \\
\hline & & & & & 1,30 \\
\hline \multirow[t]{3}{*}{$\mathrm{Ca}$} & Folha & $\mathrm{Ca}=-0,004 \mathrm{P} 2+0,163 \mathrm{P}+7,66$ & $0,71^{*}$ & 9,3 & 0,21 \\
\hline & Caule & $\mathrm{Ca}=2,947 \mathrm{~ns}$ & - & - & 0,14 \\
\hline & & & & & 0,35 \\
\hline \multirow[t]{3}{*}{$\mathrm{Mg}$} & Folha & $\mathrm{Mg}=-0,1172 \mathrm{P}+6,142$ & $0,45^{*}$ & 3,8 & 0,09 \\
\hline & Caule & $M g=-0,0017 P 2+0,08 P+0,75$ & $0,71^{*}$ & - & 0,08 \\
\hline & & & & & 0,17 \\
\hline \multirow[t]{3}{*}{$S$} & Folha & $S=-0,0023 P 2+0,095 P+2,01$ & $0,90^{* *}$ & 3,0 & 0,07 \\
\hline & Caule & $S=0,676 n s$ & - & - & 0,03 \\
\hline & & & & & 0,10 \\
\hline \multirow[t]{3}{*}{$B$} & Folha & $B=35,018 n s$ & - & 35,0 & 0,79 \\
\hline & Caule & $B=13,0127 n s$ & - & - & 0,61 \\
\hline & & & & & 1,40 \\
\hline \multirow[t]{3}{*}{$\mathrm{Cu}$} & Folha & $\mathrm{Cu}=7,6368 \mathrm{~ns}$ & - & 7,6 & 0,17 \\
\hline & Caule & $\mathrm{Cu}=4,866 \mathrm{~ns}$ & - & - & 0,23 \\
\hline & & & & & 0,40 \\
\hline \multirow[t]{3}{*}{$\mathrm{Fe}$} & Folha & $\mathrm{Fe}=6,1977 \mathrm{P}+200,825$ & $0,93^{* *}$ & 322,6 & 7,27 \\
\hline & Caule & $\mathrm{Fe}=60,1655 \mathrm{~ns}$ & - & - & 2,82 \\
\hline & & & & & 10,09 \\
\hline \multirow[t]{3}{*}{$\mathrm{Mn}$} & Folha & $M n=145,135 n s$ & - & 145,1 & 3,27 \\
\hline & Caule & $\mathrm{Mn}=27,987 \mathrm{~ns}$ & - & - & 1,31 \\
\hline & & & & & 4,58 \\
\hline \multirow[t]{3}{*}{$\mathrm{Zn}$} & Folha & $Z n=21,278 n s$ & - & 21,3 & 0,48 \\
\hline & Caule & $\mathrm{Zn}=12,272 \mathrm{~ns}$ & - & - & 0,58 \\
\hline & & & & & 1,06 \\
\hline
\end{tabular}

${ }^{1}$ Acúmulo dos macro $\left(\mathrm{g}\right.$ planta $\left.{ }^{-1}\right)$ e micronutrientes $\left(\mathrm{mg} \mathrm{planta}^{-1}\right)$ na parte aérea das plantas (caule + folha).

$*, * *,{ }^{n s}$ - Significativo a $1,5 \%$ e não significativo, respectivamente, pelo teste de $\mathrm{F}$.

foliar da planta de menta, na prática seria mais interessante. Isso devido ao menor gasto com o nutriente; possível aumento do número de plantas por área e, menor peso de folhas a ser processado pela indústria para a extração da mesma quantidade de óleo.

Teores foliares e acúmulo de nutrientes na parte aérea aos 95 DC

As concentrações de $\mathrm{P}$ na solução nutritiva influenciaram significativamente os teores foliares de $\mathrm{N}, \mathrm{P}, \mathrm{K}, \mathrm{Ca}, \mathrm{Mg}$, $\mathrm{S}$ e $\mathrm{Fe}$, porém não afetaram os teores foliares de B, Cu, Mn e Zn (Tabela 2).

Os teores foliares de $\mathrm{P}$ apresentaram uma relação direta com as concentrações de P na solução nutritiva, com ajuste linear entre as variáveis. As concentrações de $\mathrm{P}$ no meio também proporcionaram aumento nos teores foliares de $\mathrm{Fe}$, com ajuste linear e dos teores foliares de N, Ca e S, com ajuste quadrático. Os teores foliares de $\mathrm{K} \mathrm{e} \mathrm{Mg}$ apresentaram redução com o incremento das concentrações de P (Tabela 2), que pode estar relacionado com o efeito de diluição proporcionado pelo aumento de produção de massa seca de folhas.

Também foram determinados os teores foliares (níveis críticos) e o acúmulo dos nutrientes na parte aérea (Tabela 2), correspondentes à concentração de $\mathrm{P}$ na solução nutritiva que proporcionou a máxima produção de óleo essencial (19,48 $\left.\mathrm{mg} \mathrm{L}^{-1}\right)$. Para o cálculo do acúmulo de nutrientes na parte aérea utilizou-se a produção de massa seca de folhas e caules, também, correspondente à concentração de 19,48 $\mathrm{mg} \mathrm{L}^{-1}$ de P, estimandose assim, a exigência nutricional da planta em relação à máxima produção de óleo essencial aos 95 DC.

Como não foram encontrados na literatura níveis críticos foliares da Mentha piperita L. para comparações, os dados estimados no presente traba- 
lho podem ser considerados um referencial nutricional da cultura. A ordem de acúmulo dos nutrientes na parte aérea, relacionada à máxima produção de óleo essencial aos $95 \mathrm{DC}$, foi $\mathrm{N}>\mathrm{K}>\mathrm{Ca}>\mathrm{P}>\mathrm{Mg}>\mathrm{S}>\mathrm{Fe}>\mathrm{Mn}>\mathrm{B}>\mathrm{Zn}>\mathrm{Cu}$, o que está de acordo com a maioria das culturas de interesse econômico (Malavolta et al., 1997). O principal destaque dessa ordem foi o maior acúmulo de $\mathrm{P}$ em relação ao $\mathrm{Mg}$. Esse resultado confirma os apresentados por Singh e Singh (1971), onde o período de desenvolvimento da planta onde há maior acúmulo de $\mathrm{P}$ coincide com o período de maior concentração de óleo essencial das plantas.

Com os resultados apresentados pode-se concluir que na segunda coleta (95 DC) obteve-se maior crescimento das plantas e teor foliar de óleo essencial. O uso de $30 \mathrm{mg} \mathrm{L}^{-1}$ de $\mathrm{P}$ na solução nutritiva foi insuficiente para as plantas atingirem o máximo crescimento de folhas e caules; a concentração de 19,48 $\mathrm{mg} \mathrm{L}^{-1}$ de $\mathrm{P}$ proporcionou o máximo teor foliar de óleo essencial; as maiores concentrações de P na solução (24 e 30 mg $\left.\mathrm{L}^{-1}\right)$, promoveram aumentos no crescimento da parte aérea da menta, mas reduziram os teores de óleo essencial, não significando, portanto, ganhos de produção de óleo por planta. Os teores foliares dos nutrientes associados ao teor máximo de óleo aos 95 DC foram (macronutrientes $\left(\mathrm{g} \mathrm{kg}^{-1}\right)$ ): $\mathrm{N}=37,2$;
$\mathrm{P}=3,9 ; \mathrm{K}=21,2 ; \mathrm{Ca}=9,3 ; \mathrm{Mg}=3,8$; $\mathrm{S}=3,0$; (micronutrientes $\left(\mathrm{mg} \mathrm{kg}^{-1}\right)$ ): $\mathrm{B}=35 ; \mathrm{Cu}=8 ; \mathrm{Fe}=323 ; \mathrm{Mn}=145$ e $\mathrm{Zn}=22$. A exigência nutricional aos 95 DC relacionada ao máximo teor de óleo essencial seguiu a seqüência: $\mathrm{N}>\mathrm{K}>\mathrm{Ca}>\mathrm{P}>\mathrm{Mg}>\mathrm{S}>\mathrm{Fe}>\mathrm{Mn}>\mathrm{B}>\mathrm{Zn}>\mathrm{Cu}$.

\section{LITERATURA CITADA}

CARDOSO, M.G.; SHAN, A.Y.K.V.; PINTO, J.E.B.P.; DELÚ FILHO, N.; BERTOLUCCI, S.K.V. Metabólitos secundários vegetais: visão geral química e medicinal. Lavras: UFLA, 2001. $81 \mathrm{p}$.

CARDOSO, M.G.; GAVILANES, M.L.; MARQUES M.C.S.; SHAN, A.Y.K.V.; SANTOS, B.R.; OLIVEIRA, A.C.B.; BERTOLUCCI, S.K.V.; PINTO, A.P.S. Óleos Essenciais. Boletim Técnico - Série Extensão, Lavras, v.8, n.58, p.1-42, 2000.

DRAGAR, V.A.; MENARY, R.C. Mineral nutrition of Olearia phlogopappa: effect on growth, essential oil yield, and composition. Commun. Soil Sci. Plant Anal., v.26, n.7e8, p.1299-1313, 1995. HOAGLAND, D.R.; ARNON, D.I. The water culture method of growing plants without soil. Un. of Calif., Berkeley, 32 p., 1950.

KOTHARI, S.K.; SINGH, V.; SINGH, K. Effect of rates and method of $\mathrm{P}$ application on herb and oil yields and nutrient concentrations in Japanese mint (Mentha arvensis L.). Journal of Agricultural Science, v.108, n.3, p.691-693, Jun. 1987.

MAIA N.B. Nutrição mineral, crescimento e qualidade do óleo essencial da menta (Mentha arvensis L.) cultivada em solução nutritiva. Piracicaba: ESALQ, 1994. 64 p. (Tese mestrado) MAIA, N.B. Produção e qualidade de óleo essencial de duas espécies de menta cultivadas em solução nutritiva. Piracicaba: ESALQ, 1998. 105 p. (Tese doutorado)
MALAVOLTA, E.; VITTI, G.C.; OLIVEIRA, S.A. DE. Avaliação do estado nutricional das plantas: princípios e aplicações. 2 ed. Piracicaba: POTAFOS, 1997. 319 p.

MARSCHNER, H. Mineral nutrition of higher plants. 2 ed. San Diego: Academic Press, 1995. $889 \mathrm{p}$.

PICCAGLIA， R.; DELLACECCA， V.; MAROTTI, M.; GIOVANELLI, E. Agronomic factors affecting the yields and the essential oil composition of peppermint (Mentha piperita L.) Acta Horticulturae, n.344, p.29-40. 1993.

PRASZNA, L.; BERNÁTH, J. Correlations between the limited level of nutrition and essential oil production of peppermint. Acta Horticulture, n.344, p.278-289, 1993.

RAIJ, B. Van. Fertilidade do solo e adubação. São Paulo: Ed. Agronômica Ceres e Associação Brasileira para a Pesquisa da Potassa e do Fosfato, $1991.343 \mathrm{p}$.

SINGH J.N.; SINGH, D.P. Effect of phosphorus deficiency on carbohydrate metabolism of Mentha arvensis. Physiologia Plantarum, Copenhagen, v.21, p.1341-1347, 1968 .

SINGH, D.P.; SINGH, J.N. Uptake and accumulation of phosphorus by Japanese mint (Mentha arvensis L. var. piperascens Holms) as affected by phosphorus deficiency. Indian Journal of Agricultural Science, v.41, n.3, p.265-270, 1971. SINGH, V.P.; SINGH, D.V. Accumulation pattern of chemical constituents in mentha species with advance of crop age and nitrogen level. Acta Horticulturae, Wageningen, 188a, p.187-189, 1989.

SUBRAHMANYAM, K.; NAIR, A.K.; CHATTOPADHYAY, A.; SINGH, D.V. Evaluation of ammonium polyphosphate as phosphorus source in japanese mint (Mentha arvensis subsp haplocalyx var piperascens). Indian Journal of Agricultural Sciences, v.62, n.8, p.5546, 1992. 